\title{
Biosynthesis and Characterization of Copper Nanoparticles from Tulasi (Ocimum sanctum L.) Leaves
}

\author{
S. Usha ${ }^{1 *}$, K.T. Ramappa ${ }^{1}$, Sharanagouda Hiregoudar ${ }^{1}$, G.D. Vasanthkumar ${ }^{1}$ \\ and D.S. Aswathanarayana ${ }^{2}$ \\ ${ }^{1}$ Department of Processing and Food Engineering, College of Agricultural Engineering, \\ University of Agricultural Sciences, Raichur- 584 104, Karnataka, India \\ ${ }^{2}$ Department of Plant Pathology, University of Agricultural Sciences, Raichur- 584 104, \\ Karnataka, India \\ *Corresponding author
}

\begin{tabular}{|c|c|}
\hline \multicolumn{2}{|r|}{ A B S T R A C T } \\
\hline & \multirow{6}{*}{$\begin{array}{l}\text { Nanotechnology is mainly concerned with synthesis of nanoparticles of variable sizes, } \\
\text { shapes, chemical compositions and controlled dispersity with their potential use for human } \\
\text { benefits. The subject nanotechnology deals with manufacturing, study and manipulation of } \\
\text { matter at nano scale in the size range of } 1-100 \mathrm{~nm} \text { which may be called as nanoparticles. } \\
\text { Development of green nanotechnology is creating interest of researchers towards eco- } \\
\text { friendly biosynthesis of nanoparticles. Biomolecules present in plant extracts can be used } \\
\text { to reduce metal ions into nanoparticles in a single-step green synthesis process. Tulasi } \\
\text { (Ocimum sanctum L.) is an aromatic plant belongs to family Lamiaceae. Tulasi is a } \\
\text { traditional medicinal plant of India, having good source of bio-reduction and stabilizers. } \\
\text { The constituent of tulasi are alkaloids, glycosides, tannins, saponins and aromatic } \\
\text { compounds and also it contains minerals like Ca, Mn, Cu, Zn, P, K, Na, and Mg where the } \\
\text { concentration of Cu is more in tulasi leaves than other leaves. It constitutes } 12.31 \mathrm{mg} / \mathrm{kg} \text { of } \\
\text { Cu. Recently Ocimum sanctum L. leaf extracts have been used in the synthesis of silver } \\
\text { nanoparticles and gold nanoparticles. Tulasi is a source of bio-reduction and stabilizers. } \\
\text { The copper is highly toxic to microorganisms such as bacteria. copper nanoparticles were } \\
\text { synthesized from various plant extracts such as Hibicus rosasinensi, Ocimum santanum } \\
\text { leaf extract, Syzygium aromaticum (Cloves), Lemon fruit extract, Vitis vinifira extract, } \\
\text { Eucalyptus, Cassia alata, Centellaasiatica, Malva sylvestris etc. Various instrumental } \\
\text { techniques were adopted to characterize the synthesized Cu NPs, viz., Dynamic light } \\
\text { scattering analyzer (Zetasizer), UV-Vis spectroscopy, FTIR, SEM, TEM and XRD. }\end{array}$} \\
\hline Keywords & \\
\hline & \\
\hline Article Info & \\
\hline & \\
\hline & \\
\hline
\end{tabular}

\section{Introduction}

The term nanotechnology, buzzword of present day science owes its origin from the Greek word 'nano' literally meaning 'dwarf'. When it is expressed in terms of dimension one nanometer equals to one billionth of a meter $\left(1 \mathrm{~nm}=10^{-9} \mathrm{~m}\right)$. The subject nanotechnology deals with manufacturing, study and manipulation of matter at nano scale in the size range of $1-100 \mathrm{~nm}$ which may be called as nanoparticles (Rajan, 2004). Nanotechnology represents the design, production and application of materials at atomic, molecular and macromolecular scales in order to produce new nanosized materials 
(Hahens et al., 2007). Nantechnology is mainly concerned with synthesis of nanoparticles of variable sizes, shapes, chemical compositions and controlled dispersity with their potential use for human benifits (Elumalai et al., 2010).

Another way that nanotechnology can be defined is by differentiating between the production processes of 'top-down' and 'bottom-up'. Top-down refers to the fabrication of nanostructures by miniaturising present methods, such as machining and etching techniques. The other approach is bottom-up, sometimes labelled as molecular nanotechnology, whereby nano-sized objects are constructed from smaller units, even down to the manipulation of individual atoms (Albrecht et al., 2006).

The increased surfaces of nanoparticles are responsible for their different chemical, optical, mechanical, magnetic properties as compared to bulk materials (Mazur, 2004). Physical and chemical methods of synthesis of nanoparticles (NPs) are expensive, time consuming, labour intensive and also requires more energy. These methods are potentially hazardous to the environment and living organisms due to use of toxic reducing and stabilizing agents (Mittal et al., 2013).

Therefore, there is a need to develop cost effective, non-toxic and eco-friendly method for synthesis of nanoparticles. Biological methods of synthesis would help to remove harsh processing conditions by enabling the synthesis at physiological $\mathrm{pH}$, temperature, pressure, and at the same time at lower cost. Large number of micro-organisms have been found to be capable of synthesizing inorganic nanoparticles composite either intra or extracellularly (Vithiya and Sen, 2011).

Development of green nanotechnology is creating interest of researchers towards eco-friendly biosynthesis of nanoparticles. Biomolecules present in plant extracts can be used to reduce metal ions into nanoparticles in a single-step green synthesis process. This biogenic reduction of metal ion is quite rapid, readily conducted at room temperature and pressure and easily scaled up (Parikh et al., 2014). It is cost effective and main advantage is eco-friendly compared to other methods like Laser ablation, arc discharge etc., (Gopinath et al., 2014). These are some of the leaves viz., neem (Azadirachta indica), sajna (Moringa oleifera), arjun (Terminalia arjuna), tulsi (Ocimum sanctum), turmeric (Curcuma longa); rhizomes of ginger (Zingiber officinale) and turmeric; fruits of amla (Emblica officinalis), haritaki (Terminalia chebula), bohera (Terminalia belerica) and bulbs of garlic (Allium sativum) which contains minerals like $\mathrm{Cu}, \mathrm{P}, \mathrm{Mg}, \mathrm{K}$ $\mathrm{Na}, \mathrm{P}, \mathrm{Zn}$ and $\mathrm{Mn}$ (Bhowmil et al., 2008).

Tulasi (Ocimum sanctum) is an aromatic plant belongs to family Lamiaceae (Kashif and Ullah, 2013). Tulasi is a traditional medicinal plant of India, having good source of bioreduction and stabilizers. The constituent of tulasi are alkaloids, glycosides, tannins, saponins and aromatic compounds and also it contains minerals like $\mathrm{Ca}, \mathrm{Mn}, \mathrm{Cu}, \mathrm{Zn}, \mathrm{P}, \mathrm{K}$, $\mathrm{Na}$, and $\mathrm{Mg}$ where the concentration of $\mathrm{Cu}$ is more in tulasi leaves than other leaves. It constitutes $12.31 \mathrm{mg} / \mathrm{kg}$ of $\mathrm{Cu}$ (Bhowmil et al., 2008). Recently Ocimum sanctum leaf extracts have been used in the synthesis of silver nanoparticles and gold nanoparticles. Tulasi is a source of bio-reduction and stabilizers (Vennila and Nithya, 2016). The copper is highly toxic to microorganisms such as bacteria. copper nanoparticles were synthesized from various plant extracts such as Hibicus rosasinensi, Ocimum santanum leaf extract, Syzygium aromaticum (Cloves), Lemon fruit extract, Vitis vinifira extract, Eucalyptus, Cassia alata, Centellaasiatica, Malva sylvestris etc. (Hariprasad et al., 2016). 
Various instrumental techniques were adopted to characterize the synthesized $\mathrm{Cu}$ NPs, viz., Dynamic light scattering analyzer (Zetasizer), UV-Vis spectroscopy, FTIR, SEM, TEM and XRD. Synthesis of colloidal $\mathrm{Cu}$ NPs was monitored by using UV-Visible spectroscopy (Joseph et al., 2016). Nanoparticles are generally characterized by their size, morphology and surface charge by using advanced microscopic techniques such as scanning electron microscopy (SEM), transmission electron microscopy (TEM) and atomic force microscopy (AFM). The average particle diameter, their size distribution and the charge they carry affect the physical stability and invivo distribution of nanoparticles. Electron microscopy techniques are very useful in ascertaining the overall shape of polymeric nanoparticles, which may determine their toxicity. The surface charge of nanoparticles affects the physical stability and redispersibility of the polymer dispersion as well as their in-vivo performance (Pal et al., 2011). Nanoparticles can serve as "magic bullets" containing herbicidal, nano-pesticidal and as fertilizers or genes, effect which target specific cellular organelles in plant and release their contents (Genady et al., 2016).

\section{Materials and Methods}

The biosynthesis of copper nanoparticles from tulasi (Ocimum sanctum L.) leaves was carried out as described below.

\section{Preparation of plant extract}

The leaves were cleaned and washed thoroughly with distilled water and subsequently dried in solar tunnel dryer at 40 ${ }^{\circ} \mathrm{C}$ for 2 days to remove moisture completely. Dried leaves were ground to make into a fine powder. The obtained powder was passed through a 20 mesh sieve $(840 \mu \mathrm{m})$ to get uniform size. $10 \mathrm{~g}$ of uniformly sized powder was taken in a beaker along with $100 \mathrm{ml}$ of deionised water and it is allowed to boil at $60^{\circ}$ $\mathrm{C}$ for $30 \mathrm{~min}$. under reflux condition and cooled down to room temperature. The prepared solution was double filtered through Whatman No.1 filter paper there by powdered leafy materials were filtered out and clear solution was obtained. The filtrate was stored at $4^{\circ} \mathrm{C}$ for further experiments (Mekal et al., 2016).

\section{Biosynthesis of copper nanoparticles}

The plant extract of tulasi leaves $(25 \mathrm{ml})$ was mixed with $100 \mathrm{ml}$ of $1 \mathrm{mM}$ aqueous copper sulphate pentahydrate $\left(\mathrm{CuSO}_{4} .5 \mathrm{H}_{2} \mathrm{O}\right)$ solution under continuous string. After complete mixing of leaf extract with precursor the mixture was kept for incubation at $31^{\circ} \mathrm{C}$ for $24 \mathrm{~h}$. A change in the colour from light green to dark green was observed and this indicated the formation of copper nanoparticles. The solution was then centrifuged at $6000 \mathrm{rpm}$ for $30 \mathrm{~min}$. followed by re-dispersion of the pellet in deionised water to remove any unwanted biological materials (Mekal et al., 2016). The details are presented in Figure 1.

\section{Characterization of biosynthesized copper nanoparticles}

Synthesized copper nanoparticles were subjected to various characterization studies for identification of size and morphology.

\section{Size analysis using zetasizer}

Zetasizer was used (dynamic light scattering) to study the average particle diameter (nm) of biosynthesized copper nanoparticles. $1 \mathrm{ml}$ copper nanoparticles were mixed in $1 \mathrm{ml}$ of distilled water. The suspension of $\mathrm{Cu}$ NPs was sonicated at $25{ }^{\circ} \mathrm{C}$ using the digital ultrasonication bath for $15 \mathrm{~min}$. After sonication, the sample was centrifuged using 
high speed centrifuge at $10000 \mathrm{rpm}$ for 10 min. The prepared sample of $\mathrm{Cu}$ NPs suspension filled in disposable cuvette upto $3 / 4^{\text {th }}$ of volume and cuvette was placed in dynamic light scattering chamber. During the analysis, settings were made in Malvern software as given in Table 1 .

The average particle diameter (nm) was recorded for all the three samples from size distribution by intensity graph (Das et al., 2014).

\section{Absorbance analysis using UV-Visible spectrophotometer}

UV-Visible spectrophotometer measures the extinction (scatter + absorption) of light passing through a sample. Nanoparticles have unique optical properties that are sensitive to the size, shape, concentration, agglomeration state and refractive index near the nanoparticles surface, which makes UVVisible for identifying, characterizing and studying the nanoparticles.

Biosynthesized copper nanoparticles were characterized by using UV- Visible spectrophotometer. The sample was prepared by diluting of $1 \mathrm{ml}$ of $\mathrm{Cu}$ NPs into $2 \mathrm{ml}$ distilled water and measuring the UV-Visible spectrum of solutions. The absorbance of the sample recorded in wavelength ranged between 400-600 nm (Mekal et al., 2016).

\section{Surface morphology analysis using scanning electron microscope (SEM)}

The scanning electron microscope (SEM) image of the test sample surface is obtained by scanning it with a high energy beam of electrons in vacuum chamber. When the beam of electrons strikes the surface of the specimen and interacts with atoms of sample, signals in the form of secondary electrons and back scattered electrons are generated that contain information about sample's surface morphology.

The morphological features of copper nanoparticles were studied by using SEM. The aluminum stub $(\sim 1 \mathrm{~cm}$ dia. $)$ was employed on sample holder and cleaned to remove surface oils or dirt by using acetone and blowing with compressed gas. The double coated conductive carbon tape was used as adhesives and pasted on stub. Thin layer of dried sample $(\sim 0.2 \mathrm{ml})$ placed on adhesive surface, then it was coated with palladium to make the samples conductive using sputter coater for about $90 \mathrm{~s}$. Sample holder was removed from the sputter coater and placed in vacuum chamber of SEM and magnification was (1 to 30,000 times) carried out to get clear morphology of copper nanoparticles at the accelerating voltage of 1 to $20 \mathrm{kV}$ with working distance of the sample at $10 \mathrm{~mm}$ (Joseph et al., 2016).

\section{Phase identification using X-ray diffraction (XRD)}

$\mathrm{X}$-ray diffraction (XRD) is a rapid analytical technique primarily used for phase identification of a crystalline material present in copper nanoparticles.

Powder diffraction pattern of copper nanoparticles was recorded in the high angle of 2 theta range $\left(0^{\circ}-80^{\circ}\right)$. Copper nanoparticles $(\sim 1 \mathrm{ml})$ were placed uniformly spread on glass sample holder and placed in scanner chamber. The set scan speed and step size $0.3 \% \mathrm{~min}$ and $0.001 \mathrm{~s}$, respectively were fixed (Djangang et al., 2015). The XRD pattern was recorded to phase identification of copper nanoparticles.

\section{Statistical analysis}

Completely randomized design was used to analyse the data. After proper analysis, data 
were accommodated in the tables as per the needs of objectives for interpretation of results. The Microsoft Excel was used for analysis and interpretation. The statistical procedures for agricultural research given by Gomez and Gomez (1976) were referred.

\section{Results and Discussion}

\section{Biosynthesis of copper nanoparticles from tulasi (Ocimum sanctum L.) leaves}

The biosynthesis of copper nanoparticles was carried out using copper sulphate pentahydrate $\left(\mathrm{CuSO}_{4} .5 \mathrm{H}_{2} \mathrm{O}\right)$ solution and tulasi leaf extract.

The reaction of nanoparticles synthesis started after the tulasi leaf extract was added into $1 \mathrm{mM}$ aqueous copper sulphate pentahydrate $\left(\mathrm{CuSO}_{4} .5 \mathrm{H}_{2} \mathrm{O}\right)$ solution. After $24 \mathrm{~h}$ of incubation, the colour of the mixture turned into dark green from light green which indicated the formation of copper nanoparicles.

The colour change was due to active molecules present in tulasi leaf extract which acted as a reducing and capping agent. The tulasi leaf extract reduced the copper metal ions into copper nanoparticles. The average size of biosynthesized copper nanoparticles obtained from $1 \mathrm{mM}$ aqueous $\left(\mathrm{CuSO}_{4} .5 \mathrm{H}_{2} \mathrm{O}\right)$ solution was found to be $37.61 \mathrm{~nm}$.

The biosynthesis of copper nanoparticles was carried out using tulasi leaf extract and $\mathrm{CuSO}_{4} \cdot 5 \mathrm{H}_{2} \mathrm{O}$. The nanoparticles synthesis reaction would initiates by addition of tulasi leaf extract in $100 \mathrm{ml}$ of $1 \mathrm{mM}$ aqueous $\mathrm{CuSO}_{4} .5 \mathrm{H}_{2} \mathrm{O}$ solution. After $24 \mathrm{~h}$ of incubation, the colour of light green mixture was turned into dark green, which indicates the formation of copper nanoparticles. The colour change was due to active molecules present in the extract which reduced the
$\mathrm{CuSO}_{4} .5 \mathrm{H}_{2} \mathrm{O}$ metal ions into copper nanoparticles.

According to Mekal et al., (2016) the synthesized copper nanoparticles were confirmed by the change of colour after addition of tulasi leaf extract into the copper sulphate solution. The leaf extract acts as both reducing and capping agent.

\section{Characterization of biosynthesized copper nanoaprticles}

The characterization of copper nanoparticles for identification of its size and morphology are given as below,

\section{Dynamic light scattering (Zetasizer) analysis}

The characterization of copper nanoparticles in terms of average particle diameter was recorded in $\mathrm{nm}$ from the intensity distribution analysis by using Zetasizer and shown in Table 2. It revealed that three biosynthesized samples with average particles diameter were $37.61 \mathrm{~nm}$

The average particle diameter $37.61 \mathrm{~nm}$ of copper nanoparticles was used for the further characterization and application.

The results of Zetasizer revealed that the average size of biosynthesized copper nanparticles was found to be $37.61 \mathrm{~d} . \mathrm{nm}$ as shown in Figure 1. This is in agreement with previous findings which suggested that, as the reaction temperature increases, both synthesis rate and conversion of copper nanoparticles increased.

The average particle size decreased from 110 $\mathrm{nm}$ at $25{ }^{\circ} \mathrm{C}$ to $45 \mathrm{~nm}$ at $95{ }^{\circ} \mathrm{C}$ (Lee et al., 2011). The variation in particle size was probably due to change in climatic conditions during biosynthesis (Zainala et al., 2013). 
Fig.1 Process flow chart for biosynthesis of copper nanoparticles from tulasi

(Ocimum sanctum L.) leaves

Tulasi (Ocimum sanctum L.) leaves

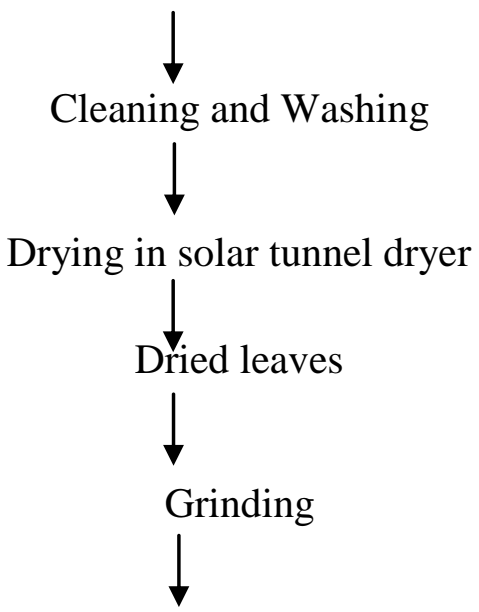

Adding $10 \mathrm{~g}$ of leaf powder in $100 \mathrm{ml}$ de-ionized water in a beaker

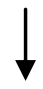

Boiling the solution at $60^{\circ} \mathrm{C}$ for 30 min under reflux condition and cooling to room temperature

Filtering the solution using Whatman filter paper No.1

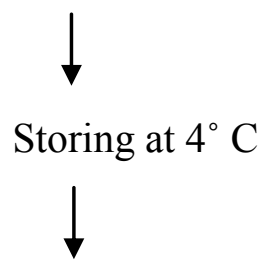

Adding $100 \mathrm{ml}$ of $1 \mathrm{mM}$ aqueous Copper sulphate pentahydrate $\left(\mathrm{CuSO}_{4} .5 \mathrm{H}_{2} \mathrm{O}\right)$ in $25 \mathrm{ml}$ tulasi leaf extract with continuous stirring

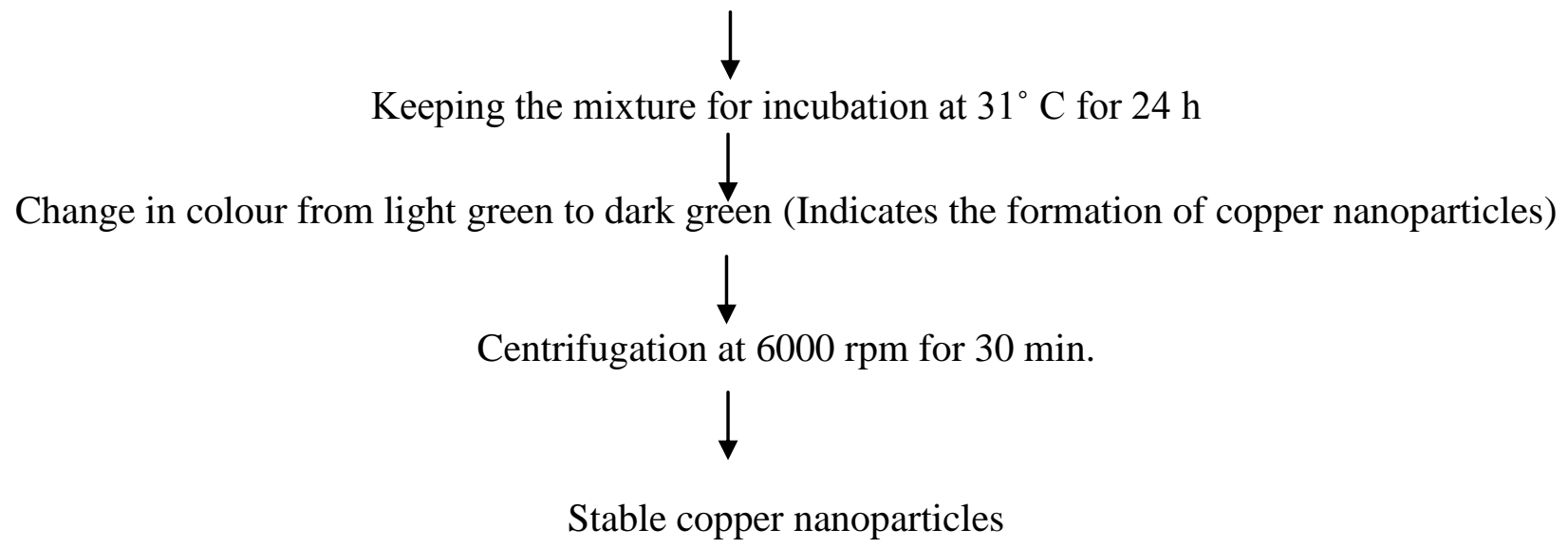


Fig.1 Z-average (d.nm) of copper nanoparticles (Cu NPs)

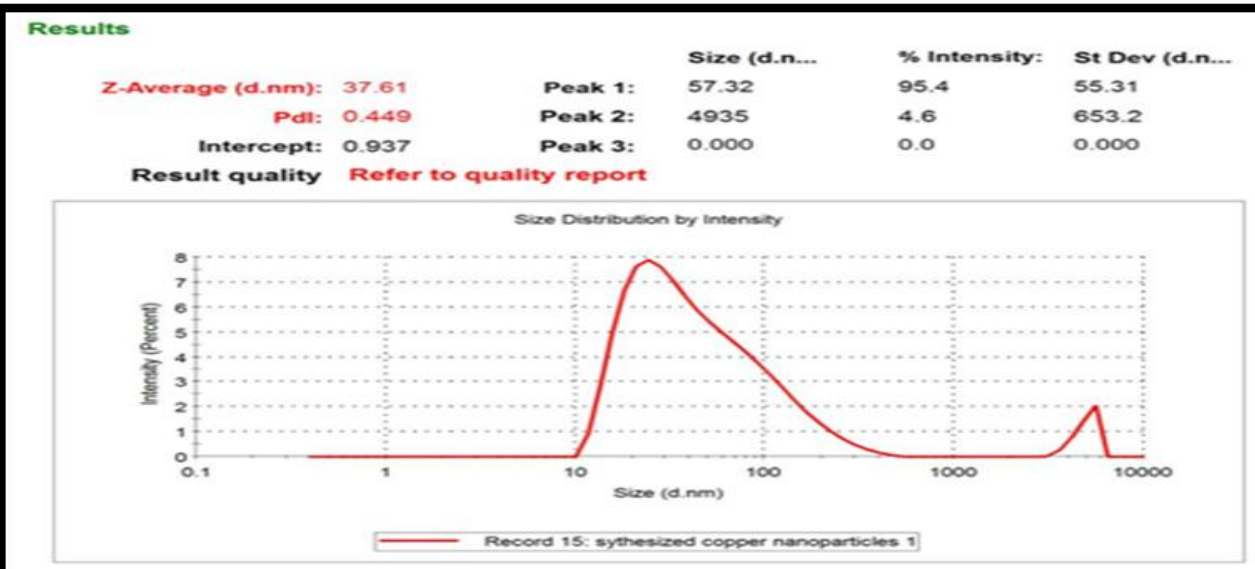

Fig.2 Absorbance value of copper nanoparticles (Cu NPs)

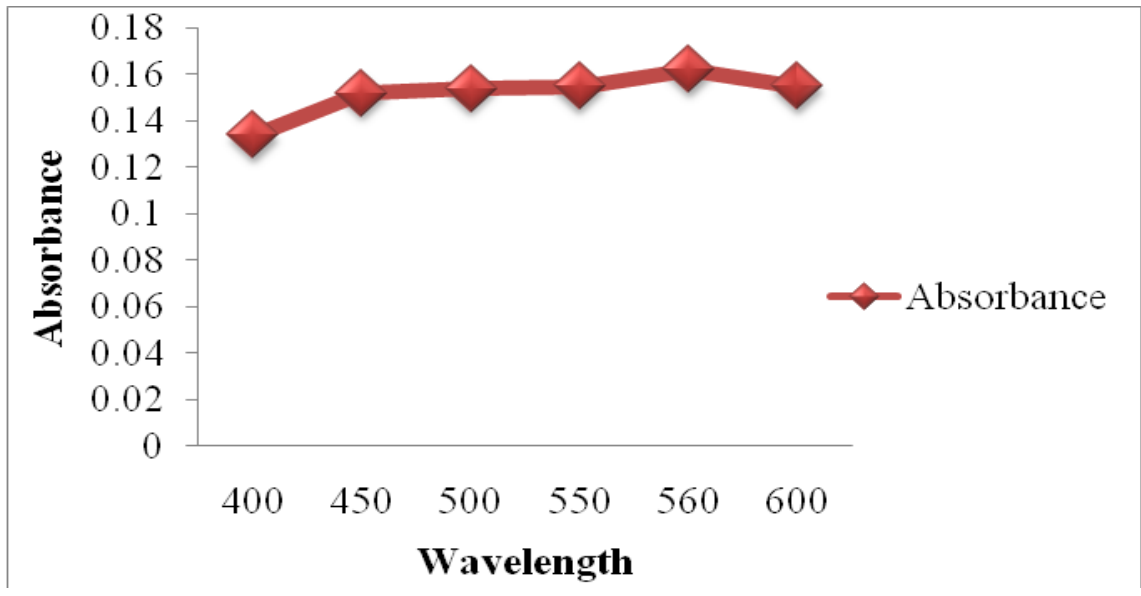

Fig.3 SEM image of copper nanoparticles (Cu NPs)

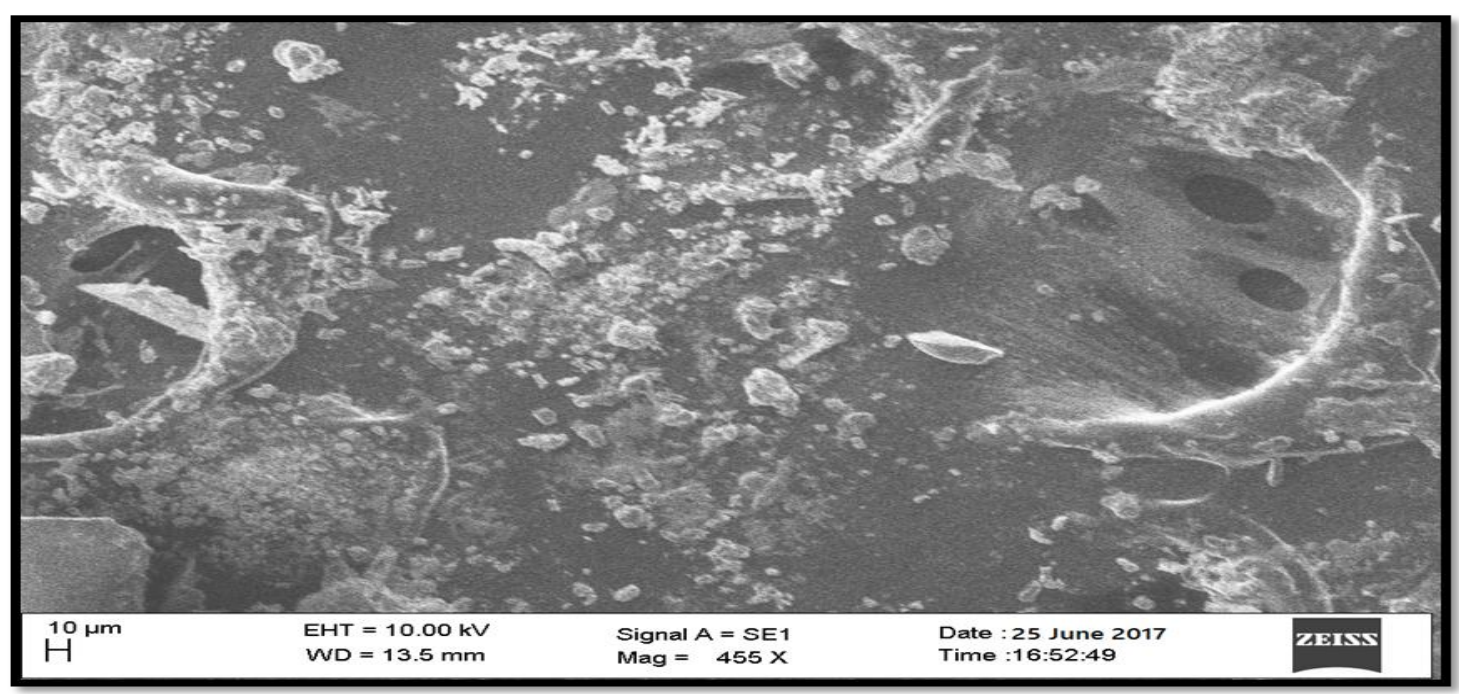


Fig.4 XRD pattern of copper nanoparticles (Cu NPs)

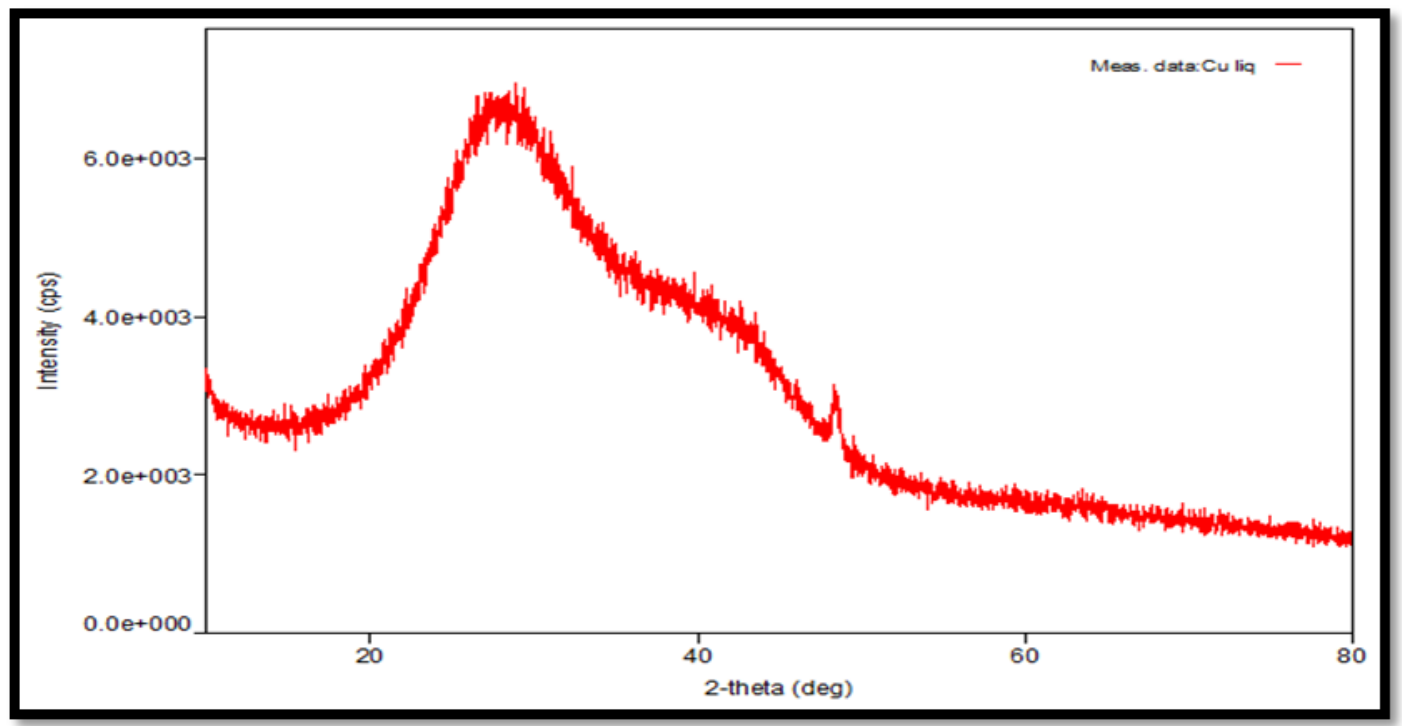

Table.1 Malvern software setting for Zetasizer analysis

\begin{tabular}{|c|c|c|}
\hline Parameters & Distilled water & Copper nanoparticles \\
\hline Viscosity & $1 \mathrm{cP}$ & - \\
\hline Refractive index & 1.36 & 1.54 \\
\hline Temperature & $20^{\circ} \mathrm{C}$ & $20^{\circ} \mathrm{C}$ \\
\hline
\end{tabular}

Table.2 Z-average (d. nm) of copper nanoparticles

\begin{tabular}{|c|c|c|c|c|c|}
\hline \multirow{2}{*}{ Sample No. } & $\begin{array}{c}\text { Z-average } \\
(\mathbf{d} . \mathbf{n m})\end{array}$ & Peak & $\begin{array}{c}\text { Size } \\
(\mathbf{d . ~} \mathbf{~ n m})\end{array}$ & $\begin{array}{c}\text { Intensity } \\
(\mathbf{\%})\end{array}$ & $\begin{array}{c}\text { St. Dev } \\
(\mathbf{d} . \mathbf{n m})\end{array}$ \\
\hline \multirow{3}{*}{1} & \multirow{3}{*}{37.61} & Peak 1 & 57.32 & 95.4 & 55.31 \\
\cline { 2 - 5 } & & Peak 2 & 4935 & 4.6 & 653.2 \\
\cline { 2 - 5 } & & Peak 3 & 0.000 & 0.0 & 0.000 \\
\hline
\end{tabular}

Table.3 UV-Visible spectrophotometer analysis of copper nanoparticles

\begin{tabular}{|c|c|c|}
\hline Sl. No. & Wavelength (nm) & Absorbance \\
\hline 1 & 400 & 0.134 \\
\hline 2 & 450 & 0.152 \\
\hline 3 & 500 & 0.154 \\
\hline 4 & 550 & 0.155 \\
\hline 5 & 560 & 0.162 \\
\hline 6 & 600 & 0.155 \\
\hline
\end{tabular}

\section{UV-Vis spectrophotometer analysis}

The UV-Visible spectrophotometer analysis shown in Table 3 revealed that different absorbance values were observed corresponding to wavelength, when wavelength band between 400-600 nm. The sharp bands of copper nanoparticles were observed at $560 \mathrm{~nm}\left(\lambda_{\max }\right)$. The UV- Visible spectrum of $\mathrm{Cu}$ NPs recorded maximum absorption band edge at $560 \mathrm{~nm}$ as 
shown in Figure 2. Saranyaadevi et al., (2014) found that the $\mathrm{Cu}$ NPs formation was confirmed from the peak at $531 \mathrm{~nm}$ with the UV range of $560-640 \mathrm{~nm}$, and hence it is evident with current result. The peak value was found to be gradually decreased with the increase in particle size. The surface plasmon vibrations of copper nanoparticles produced a peak at near $562 \mathrm{~nm}$ (Hariprasad et al., 2016).

\section{Scanning electron microscope (SEM) analysis}

The clear magnified SEM image at the accelerating voltage of $10 \mathrm{kV}$ with working distance of the sample at $13.5 \mathrm{~mm}$, showed that nanoparticles were in spherical with uniform shape distribution. SEM analysis was showed that the copper nanoparticles were spherical in shape as shown in Figure 3. Similar results were observed by Saranyaadevi et al., (2014) and Hariprasad et al., (2016) i.e. spherical in shape of copper nanoparticles.

\section{X-ray diffraction (XRD) analysis}

X-ray diffraction pattern of the copper nanoparticles showed broad halo at about $2 \theta=$ $20-40^{\circ}$ region which confirms the amorphous nature of $\mathrm{Cu}$ NPs.

Figure 4 showed the X-ray diffraction pattern of the copper nanoparticles and it showed the broad halo at about $2 \theta=20-40^{\circ}$ region which confirms the amorphous structure of $\mathrm{Cu}$ NPs. Saranyaadevi et al., (2014) was found that the XRD spectrum at two different diffraction peaks at $39.1^{\circ}$ and $68.3^{\circ}$ region and diffraction peaks obtained at $2 \theta$ angle. Peaks observed at $2 \theta$ values of $42.47^{\circ}$ by Fatma et al., (2017).

Copper nanoparticles were synthesized from tulasi leaves and characterized by various analytical techniques. Dynamic light scattering (Zetasizer) analysis data showed that the average particles diameter of $37.61 \mathrm{~nm}$ were used for the further characterization and applications. The UV- Visible spectrum of $\mathrm{Cu}$ NPs recorded maximum absorption sharp band edge at $560 \mathrm{~nm}$. SEM analysis data showed that the copper nanoparticles were in spherical shape. XRD pattern of biosynthesized copper nanoparticles revealed that, copper nanoparticles were in the amorphous form.

\section{References}

Albrecht, M. A., Evans, C. W. and Raston, C. L., 2006, Green chemistry and health implications of nanoparticles. Green chem., 8: 417-432.

Bhowmil, S., Chowdhury, S. D., Kabir, M. H. and Ali, M. A., 2008, Chemical composition of some medicinal plant products of indigenous origin. The Bangladesh Veterinarian. 25(1): 32 - 39.

Das, D., Yang, Y., O'Brien, J. S., Breznan, D., Nimesh, S., Bernatchez, S., Hill, M., Sayari, A., Vincent, R. and Kumarathasan, P., 2014, Synthesis and physicochemical characterization of mesoporous $\mathrm{SiO}_{2}$ nanoparticles. $J$. Nanomater., 62(6): 11-12.

Djangang, C, N., Mlowe, S., Njopwouo, D. and Revaprasadu, N., 2015, One-step synthesis of silica nanoparticles by thermolysis of rice husk ash using non toxic chemicals ethanol and polyethylene glycol. J. Applicable. Chem., 4(4): 12181226.

Elumalai, E. K., Prasad, V. K., Hemachandran, J., Therasa, S. V., Thirumalai, T. and David, E., 2010, Extracellular synthesis of silver nanoparticles using leaves of Euphorbia hirta and their antibacterial activities. J. Pharm. Sci. Res., 2(9): 549554.

Fatma, S., Kalainila, P., Ravindran, E. and Renganathan, S., 2017, Green synthesis of copper nanoparticle from Passiflora foetida leaf extract and its antibacterial activity. Asian. J. Pharm. Clin. Res., 10(4): 79-83.

Genady, E. A., Qaid, E. A. and Fahmy, A. H., 2016, Copper sulfate nanoparticales in vitro applications on Verbena bipinnatifida Nutt. stimulating growth and total phenolic content increasments., Int. 
J. Pharm. Res and Allied Sci., 5(1): 196202.

Gomez, K. A. and Gomez, A. A., 1976, Statistical procedures for agricultural research. A Wiley Inter Science Publications, New York.

Gopinath, M., Subbaiya, R., Selvam, M. M. and Suresh, D., 2014, Synthesis of copper nanoparticles from Nerium oleander leaf aqueous extract and its antibacterial activity, Int. J. Curr. Microbiologic. App. Sci., 3(9): 814-818.

Hahens, W. I., Oomen, A. G., Dejong, W. H., Cassee, F. R., 2007, What do we (need to) know about the kinetic properties of nanoparticles in the body. Regulatory Toxicology and Pharmacology, 49: 217229.

Hariprasad, S., Bai, G. S., Santhoshkumar, J., Madhu, C. H. and Sravani, D., 2016, Green synthesis of copper nanoparticles by Arevalanata leaves extract and their antimicrobial activites. Int. J. Chem Tech. Res., 9(2): 98-105.

Joseph, A. T., Prakash, P. and narvi, S. S., 2016, Phytofabrication and characterization of copper nanoparticles using Allium sativum and its antibacterial activity. Int. J. Sci. Eng. Tech., 4(2): 463-472.

Kashif, M. and Ullah, S., 2013, Chemical composition and minerals analysis of Hippophae rhamnoides, Azadirachta indica, Punica granatu and Ocimum sanctum leaves., World J. Dairy and Food Sci., 8(1): 67-73.

Lee, H. J., Lee, G., Jang. N. R., Yun, J. H., Song, J. Y. and Soo, B., 2011, Biological synthesis of copper nanoparticles using plant extract. Bioprocess Bio. Syst. Eng., 1: 371-374.

Mazur, M., 2004, Electrochemically prepared silver nanoflakes and nanowires, Electrochem. Commun., 6(4): 400-403.

Mekal, J., Rajan, M. R. and Ramesh, R., 2016, Green synthesis and characterization of copper nanoparticles using tulsi (Ocimum sanctum) leaf extract. Indian J. Research, 5(2): 14-16.

Mittal, A. M., Chisti, Y. and Banerjee, Y. A., 2013, Synthesis of metallic nanoparticles using plant extracts. Biotech. Adv., 31(2): 346-356.

Pal, S. L., Jana, U., Manna, P. K., Mohanta, G. P. and Manavalan, R., 2011, Nanoparticle: An overview of preparation and characterization. Int. J. App. Phar. Sci. 1(6): 228-234.

Parikh, P., Zala, D. and Makwand, B. A., 2014, Biosynthesis of copper nanoparticles and their antimicrobial activity, $K S V$ University, India. Pp.1-15.

Rajan, M. S., 2004, Nano: The Next Revolution. National Book Trust, India. pp. 15-72.

Saranyaadevi, K., Subha, V., Ernest, R. S and Renganathan, S., 2014, Synthesis and characterization of copper nanoparticle using capparis zeylanica leaf extract. Int. J. ChemTech. Res., 8(10): 4533-4541.

Vennila, S. and Nithya, T, 2016, Green synthesis of copper, silver nanoparticles using Ocimum tenuiflorum leaf extract. World J. Pharm. Res. 6(1): 257-265.

Vithiya, K. and Sen, S., 2011, Biosynthesis of nanoparticles. IJPSR. 2(11): 2781-2785.

Zainala, M. H., Saad, R., Ahmad, F. and Wijeyesekera, D. C., 2013, Characterisation of nanoparticle through SEM, FTRI, XRD and DSC. J. Appl. Pharm. Sci., 1(6): 228-234.

\section{How to cite this article:}

Usha, S., K.T. Ramappa, Sharanagouda Hiregoudar, G.D. Vasanthkumar and Aswathanarayana, D.S. 2017. Biosynthesis and Characterization of Copper Nanoparticles from Tulasi (Ocimum sanctum L.) Leaves. Int.J.Curr.Microbiol.App.Sci. 6(11): 2219-2228.

doi: https://doi.org/10.20546/ijcmas.2017.611.263 